\section{Inhibition of the NLRP3 inflammasome prevents ovarian aging}

\author{
José M. Navarro-Pando ${ }^{1 *}$, Elísabet Alcocer-Gómez ${ }^{2 *}$, Beatriz Castejón-Vega ${ }^{3}$, \\ Elena Navarro-Villarán ${ }^{4,5}$, Mónica Condés-Hervás ${ }^{1}$, María Mundi-Roldan ${ }^{1}$, Jordi Muntané ${ }^{4,5,6}$, \\ Antonio J. Pérez-Pulido ${ }^{7}$, Pedro Bullon ${ }^{3}$, Chun Wang ${ }^{8}$, Hal M. Hoffman ${ }^{9}$, Alberto Sanz ${ }^{3}$, \\ Gabriel Mbalaviele ${ }^{8}$, Bernhard Ryffel ${ }^{10,11}$, Mario D. Cordero ${ }^{1,12 \dagger}$
}

Inflammation is a hallmark of aging and is negatively affecting female fertility. In this study, we evaluate the role of the NLRP3 inflammasome in ovarian aging and female fertility. Age-dependent increased expression of NLRP3 in the ovary was observed in WT mice during reproductive aging. High expression of NLRP3, caspase-1, and IL-1 $\beta$ was also observed in granulosa cells from patients with ovarian insufficiency. Ablation of NLRP3 improved the survival and pregnancy rates and increased anti-Müllerian hormone levels and autophagy rates in ovaries. Deficiency of NLRP3 also reduced serum FSH and estradiol levels. Consistent with these results, pharmacological inhibition of NLRP3 using a direct NLRP3 inhibitor, MCC950, improved fertility in female mice to levels comparable to those of $\mathrm{NIrp3}^{-/-}$mice. These results suggest that the NLRP3 inflammasome is implicated in the age-dependent loss of female fertility and position this inflammasome as a potential new therapeutic target for the treatment of infertility.
Copyright @ 2021

The Authors, some rights reserved; exclusive licensee American Association for the Advancement of Science. No claim to original U.S. Government Works. Distributed under a Creative Commons Attribution NonCommercial License 4.0 (CC BY-NC).

\section{INTRODUCTION}

Aging is a natural process in all animals involving a progressive impairment of physiological and metabolic homeostasis characterized by many changes in body composition, insulin resistance, mitochondrial and autophagy dysfunction, inflammation, and hormonal dysregulation (1). From a clinical point of view, aging is associated with many signs of illness such as cardiovascular, neurodegenerative, and metabolic disorders, which are known as age-dependent diseases. These pathologies can be managed by different strategies including pharmacological intervention, lifestyle modifications, and prevention of harmful environmental exposures. However, the ovarian aging process is currently a pharmacologically uncontrollable process that impairs female fertility; the infertility correlates with a rapid decline after age 35 and is attributable to the impairment of the quantity and/or the quality of oocytes (2). Female infertility is exacerbated by socioeconomic changes in developed countries, which enable women to progressively delay the age at which they

\footnotetext{
${ }^{1}$ Cátedra de Reproducción y Genética Humana del Instituto para el Estudio de la Biología de la Reproducción Humana (INEBIR)-Universidad Europea del Atlántico (UNEATLANTICO)-Fundación Universitaria Iberoamericana (FUNIBER), Seville, Spain. ${ }^{2}$ Departamento de Psicología Experimental, Facultad de Psicología, Universidad de Sevilla, Seville, Spain. ${ }^{3}$ Institute of Molecular, Cell and Systems Biology, University of Glasgow, Glasgow G12 8QQ, UK. ${ }^{4}$ Institute of Biomedicine of Seville (IBiS), Hospital University Virgen del Rocío/CSIC/University of Seville, Seville, Spain. ${ }^{5}$ Spanish Network for Biomedical Research in Hepatic and Digestive Diseases (CIBERehd), Carlos III Health Institute (ISCIII), Madrid, Spain. ${ }^{6}$ Department of General Surgery, Hospital University Virgen del Rocío/CSIC/University of Seville/IBIS, Seville, Spain. ${ }^{7}$ Centro Andaluz de Biologia del Desarrollo (CABD, UPO-CSIC-JA), Facultad de Ciencias Experimentales (Área de Genética), Universidad Pablo de Olavide, 41013 Seville, Spain. ${ }^{8}$ Division of Bone and Mineral Diseases, Washington University School of Medicine, St. Louis, MO 63110, USA. ${ }^{9}$ Division of Pediatric Allergy, Immunology, and Rheumatology, Rady Children's Hospital and University of California San Diego, La Jolla, CA 92093, USA. ${ }^{10}$ Laboratory of Experimental and Molecular Immunology and Neurogenetics (INEM), UMR 7355 CNRS-University of Orleans, Orléans, France. ${ }^{11}$ IDM, University of Cape Town, Cape Town, South Africa. ${ }^{12}$ Instituto de Investigación e Innovación en Ciencias Biomédicas de Cádiz (INiBICA), Cadiz, Spain.

*These authors contributed equally to this work.

tCorresponding author.Email: mdcormor@ugr.es
}

have their first child. As a consequence, there is increased demand for the treatment of infertility (3). One of the key events that contribute to ovarian aging includes follicular atresia as it is associated with the breakdown of the ovarian follicles in both physiological and premature ovarian aging (2). Follicular atresia, as an associated event to cellular aging, show many pathophysiological alterations associated with physiological aging such as mitochondrial dysfunction, oxidative stress, and inflammation, and as aging itself, it is sensitive to stress $(1-3)$.

Although inflammation can negatively affect female fertility (4), the underlying molecular mechanisms are poorly understood. Preliminary studies in animal models have shown that genetic deletion of tumor necrosis factor (TNF) receptor improves female fertility and deletion of interleukin-1 $\alpha$ (IL- $1 \alpha)$ mice has prolonged the life span of the ovaries $(5,6)$.

The NLR family pyrin domain containing 3 (NLRP3) inflammasome is one of the most well-studied inflammasomes in humans and mice (1). It is a multiprotein complex comprising NLRP3 itself as an intracellular sensor, the adapter protein ASC [apoptosis-associated speck-like protein containing a CARD (caspase recruitment domain)], and procaspase-1. Two steps are required for the activation of this protein platform. The first step, also known as priming signals, causes the transcription of inflammasome constituents, a response that is mediated by nuclear factor $\mathrm{\kappa B}$ and other pathways such as $\mathrm{p} 38$ mitogenactivated protein kinase (7). Signal two, or triggering, is induced by pathogen-associated molecular patterns, and stress-associated signals or host-derived damage-associated molecular patterns lead to NLRP3 oligomerization complex assembly (8), and caspase- 1 activation activated caspase- 1 of caspase- 1 process pro-IL- $1 \beta$ and pro-IL-18 to IL-1 $\beta$ and IL-18, respectively. This inflammasome is also involved in the processing of the pore-forming protein gasdermin $\mathrm{D}$ whose excessive pore formation can cause an inflammatory form of cell death known as pyroptosis (8). The NLRP3 inflammasome is activated by a range of danger and stress signals $(8)$, some of which rise during aging (1). Thus, NLRP3 inflammasome can contribute to a vicious cycle of low-grade inflammation that occurs during aging. 
Genetic deletion of Nlrp3 in mice has been shown to improve life span and health by attenuating multiple age-related degenerative changes such as cardiac aging, insulin sensitivity with glycemic control, and bone loss $(9,10)$. However, the role of the NLRP3 inflammasome in ovarian aging and female age-related fertility decline has not been studied. Therefore, we sought to determine whether genetic deletion of NLRP3 could have an effect on ovarian aging and potentially prevent the decline of female fertility.

\section{RESULTS}

\section{The NLRP3 inflammasome is activated during ovarian aging}

To evaluate the role of the NLRP3 inflammasome in ovarian aging, we examined ovaries from female mice of different ages. Wild-type (WT) C57BL/6J female mice exhibited a substantial increase in body weight over a 12-month period (Fig. 1A) and a significant decrease in anti-Müllerian hormone $(\mathrm{AMH})$ after the sixth month of life (Fig. 1B). NLRP3 protein expression was increased from the fourth month alongside the levels of active caspase-1 (p20) and an age-dependent increase of active IL-1 $\beta$ (p17; Fig. 1, C and D). NLRP3 expression was observed in the cytoplasm of granulosa cells (GCs) and follicles of different status including atretic follicles, in the cytoplasm of oocytes, and in the glandular epithelium of the uterus (Fig. 1E, negative control and magnification in figs. S1 to S3). Notably, NLRP3 expression in these tissues was higher in aged animals. NLRP3 expression was inversely correlated with serum AMH levels (Fig. 1F). Since autophagic dysfunction has also been linked to aging, we analyzed the expression of the components in this pathway. We observed an increase in the expression of microtubule-associated protein 1 light chain 3 (LC3-II) and other proteins involved in clearance pathways such as p62/SQSTM beginning at 6 months (Fig. 1, C and D).

To translate our murine studies to humans, we evaluated NLRP3 inflammasome activation in GCs from human patients with accelerated ovarian aging disease. Diminished ovarian reserve (DOR) is a critical fertility defect characterized by an anticipated impairment of the follicular reserve for which pathophysiological mechanisms are not understood. Different genetic and molecular alterations have been proposed, such as mutations in genes associated with DNA repair or meiosis, bioenergetics alterations, and mitochondrial dysfunction (2). The clinical characteristics of patients with DOR and controls are listed in table $\mathrm{S} 1$, and low ovarian reserve was confirmed by transvaginal ultrasound. Patients with DOR showed altered hormonal status compared to the control group (table S1). Follicle-stimulating hormone (FSH) levels in these patients were above $10 \mathrm{mUI} / \mathrm{ml}$, and estradiol (E2; a sexual hormone involved in the regulation of the estrous and menstrual female reproductive cycles) levels were above $60 \mathrm{pg} / \mathrm{ml}$. We found significantly increased NLRP3 mRNA and protein expression in GCs from patients with DOR compared to healthy controls. We also observed elevated protein expression of active caspase-1 (p20) and IL-1 $\beta$ (p17) (Fig. 1, G and H). However, plasma levels of TNF- $\alpha$, but not IL-1 $\beta$ and IL-18, were increased in patients with DOR compared to healthy controls (table S1).

\section{NLRP3 expression correlates with reproductive aging}

To evaluate the impact of NLRP3 expression on female fertility during aging, we monitored the life span and reproductive capacity of $\mathrm{Nlrp3}^{-/-}$and WT littermates. Kaplan-Meier survival curve showed an increase in mean life span of $37 \%$ and maximum life span of $24 \%$ in $N \mathrm{Nrp3}^{-/-}$(Fig. 2A), whereas body weights did not differ between both groups (Fig. 2B). Twelve-month-old female $\mathrm{Nlrp}^{-/-}$mice exhibited a significant decrease in glucose serum levels at the Oral glucose tolerance tests $(O G T T)$ peak (>15 min) compared to old WT mice (fig. S4A), indicating a higher glucose tolerance consistent with a trend toward lower values of the area under the curve of the glucose tolerance test (fig. S4B). Furthermore, 12-month-old female Nlrp3 ${ }^{-/-}$ mice showed no significant difference in serum levels of leptin compared to WT but an increased level of adiponectin (fig. S4, C and D). Twenty eight-month-old WT animals displayed increased age-related alopecia compared to Nlrp3 knockout (KO) mice (Fig. 2C). AMH serum levels were similar in 2-month-old WT and Nlrp3-1mice but were afterward significantly higher in mutant mice compared to WT mice (Fig. 2D). Consistent with serum levels, ovarian AMH protein levels were higher in aged (12 months old) $N l r p 3^{-/-}$ mice compared to WT mice (Fig. 2D). In addition, the levels of the sex hormones E2 and FSH increased between 4 and 12 months in WT mice but not in $\mathrm{Nlrp}^{-/-}$mice (Fig. 2, E and F). The WT group showed a markedly enlarged uterine size and weight (hypertrophic uterus) compared to $\mathrm{Nlrp3}^{-/-}$(Fig. 2G). We also analyzed the number of ovarian follicles by histological staining in ovaries from 4- and 12-month-old Nlrp3 $3^{-/-}$mice, and they showed more dynamic activity at 12 months and a greater percentage of follicles at 4 and 12 months compared with WT mice. $N l r p 3^{-/-}$ovaries retained a larger pool of follicles, which appeared more active in folliculogenesis and contained many corpora lutea, observations suggesting successful ovulation (Fig. 2, $\mathrm{H}$ and I).

A significant reduction of the pregnancy rate was observed in WT mice during aging but was markedly preserved in aged (12-month-old) $\mathrm{Nlrp3}^{-/-}$mice compared with WT mice (Fig. 3A). These observations were consistent with $\mathrm{AMH}$ and ovary data. Mean litter size was also significantly larger in 12-month-old $\mathrm{Nlrp}^{-/-}$mice compared with littermate mice as in young mice (4 months; Fig. 3B). The loss of the ASC, which has a pivotal role in the assembly of several inflammasomes (8), did not affect the agedependent loss of female fertility. $A s c^{-/-}$mice showed similar levels of $\mathrm{AMH}, \mathrm{FSH}$, and $\mathrm{E} 2$ during aging and reduced $\mathrm{AMH}$ protein expression (fig. S5, A to C). The pregnancy rate and mean litter size in $\mathrm{Asc}^{-/-}$mice were not statistically different compared with WT mice (fig. S5, D and E). These observations suggest that NLRP3 attenuates the process of ovarian aging independent of ASC expression. To reinforce the role of NLRP3 in female fertility, we studied the effects of a gain-of-function NLRP3 mutant associated with neonatal-onset multisystem inflammatory disease (NOMID) in mice (11), which showed data consistent with infertility (fig. S6, A to D).

\section{Age-related autophagic and apoptotic changes in the ovaries are prevented by NIrp3 ablation}

Blockade of autophagic flux and accumulation of nondegraded substrates in the form of autophagosome are linked to aging (12). Furthermore, apoptosis and autophagy are involved in the process of oocyte loss $(13,14) . N \operatorname{lrp} 3^{-/}$female mice showed increased levels of ATG12, beclin 1, and LC3-II protein and reduced expression of p62/ SQSTM1 compared with an accumulation of LC3-I with p62-aged WT mice associated with an impairment of autophagy (Fig. 3C). Apoptosis has been associated with ovary aging and inflammation (6). The expression of the proapoptotic protein BCL2-associated X protein (BAX) was also substantially lower in 12-month-old $N l r p 3^{-/-}$ovaries compared with WT ovaries despite no significant changes in the antiapoptotic 
A

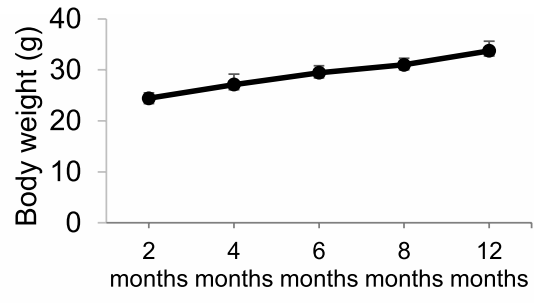

B

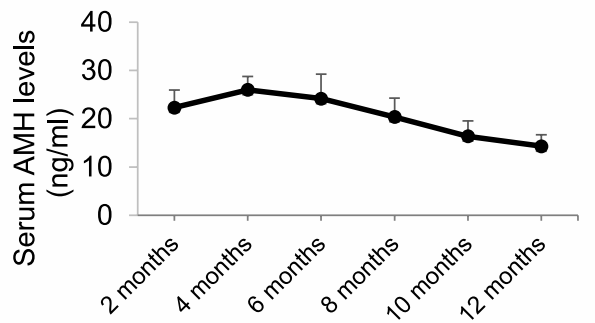

E

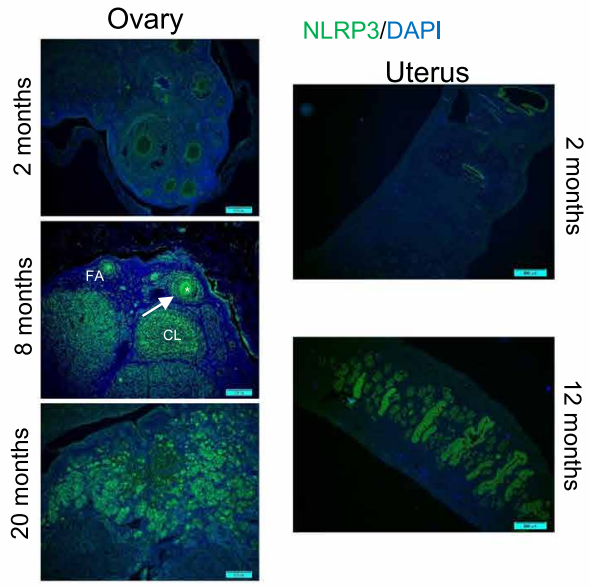

G

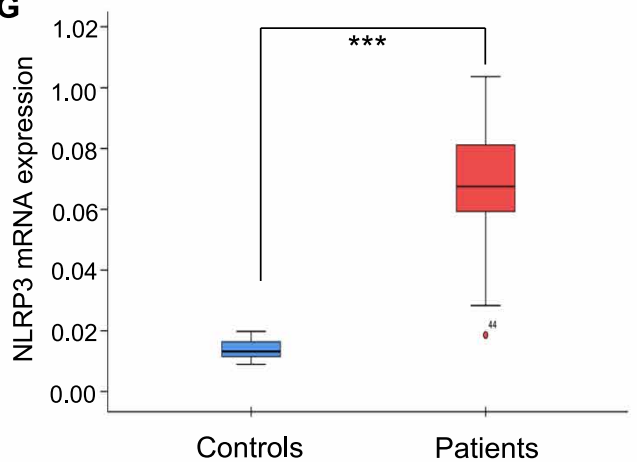

C Ovary from WT mice
2 from
months months months months months months

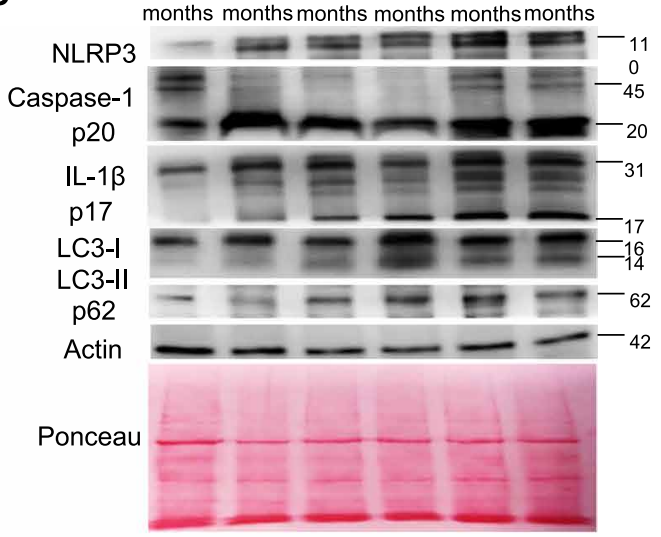

D
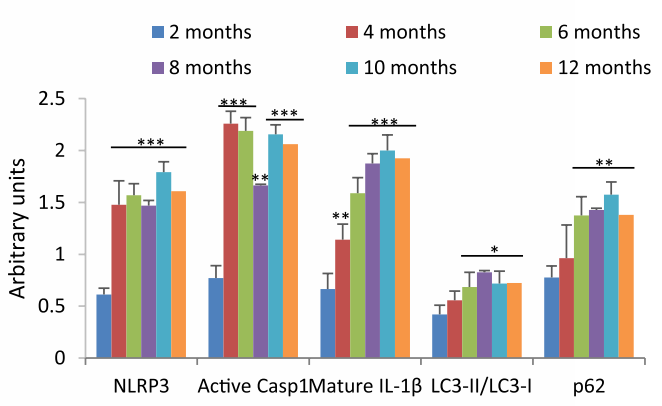

F

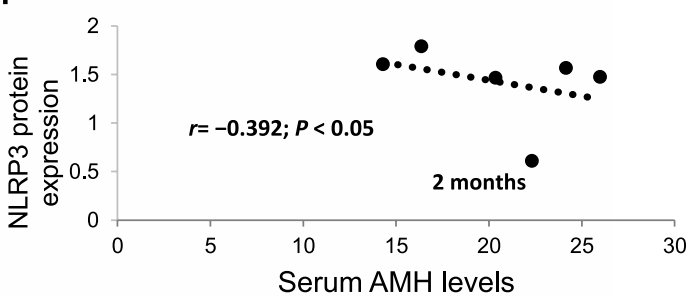

H

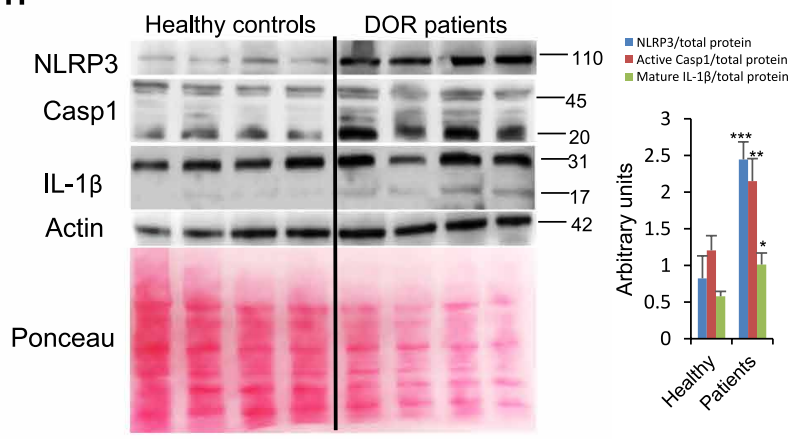

Fig. 1. NLRP3 signaling is associated with ovarian aging. (A) Body weight progression of female C57BL6/J mice evaluated per month. (B) Mean serum AMH levels to evaluate the progression of ovarian reserve during aging. $N=8$ per group. (C and D) Western blot analysis with representative blots including NLRP3, caspase-1, IL-1 $\beta$, LC3, and p62 levels in the ovary of WT mice at different ages. Densitometric analysis is shown as mean \pm SD, $n=10$ mice; ${ }^{*} P<0.05$, ${ }^{* *} P<0.005$, and ${ }^{* * *} P<0.001 ; 2$ months old versus other ages. $N=6$ to 8 per group. (E) Immunofluorescence (IF) visualization of NLRP3 (green) and nuclei (blue) in ovary and uterus tissues from young and old WT mice. Oocyte (asterisk), GCs (arrows), corpus luteum (CL), and follicular atresia (FA). DAPI, 4',6-diamidino-2-phenylindole. (F) Correlation of NLRP3 expression versus serum AMH levels during aging. The correlation was established by calculating correlation coefficients. (G) Human NLRP3 transcript expression levels were determined in GCs by real-time quantitative reverse transcription polymerase chain reaction (PCR); $n=20$ for control and $n=20$ for DOR groups. (H) Western blot analysis with representative blots including NLRP3, caspase-1, and IL-1 $\beta$ levels in GCs from four representative patients with DOR compared to four representative age-matched controls. Densitometric analysis is shown as mean $\pm \mathrm{SD}$. ${ }^{*} P<0.05,{ }^{* *} P<0.005$, and ${ }^{* * *} P<0.001$; control versus patients. 
A

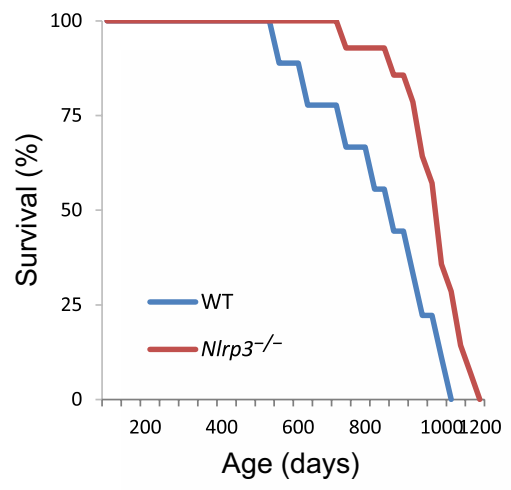

D

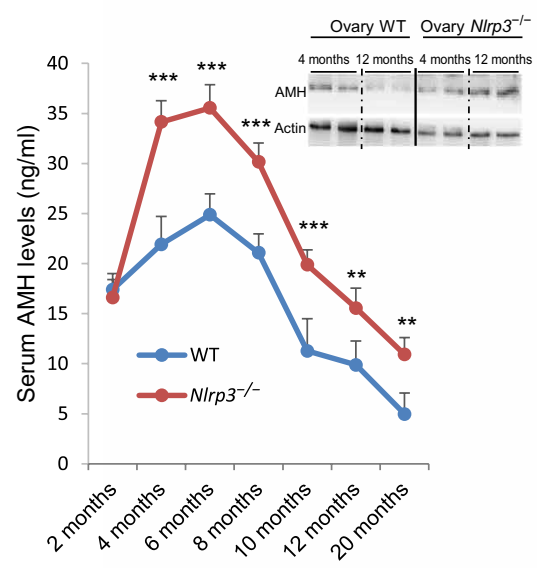

G

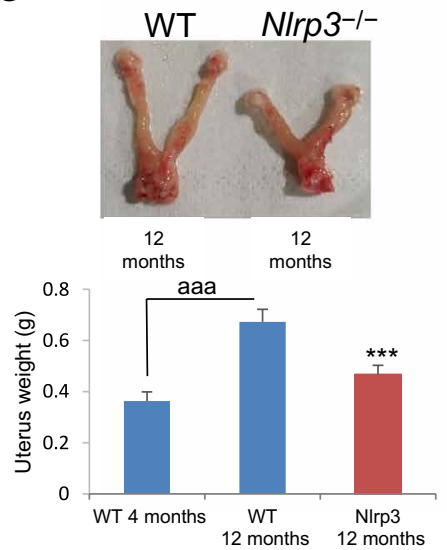

B

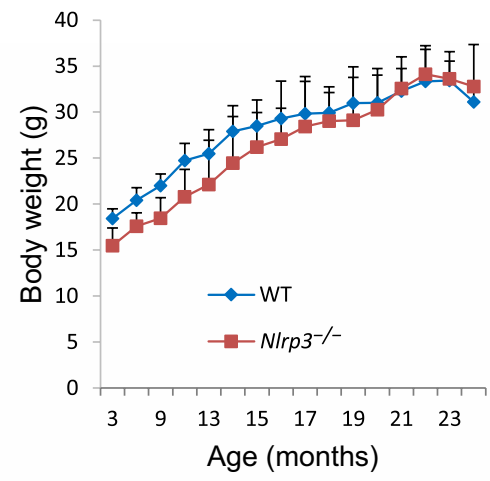

C

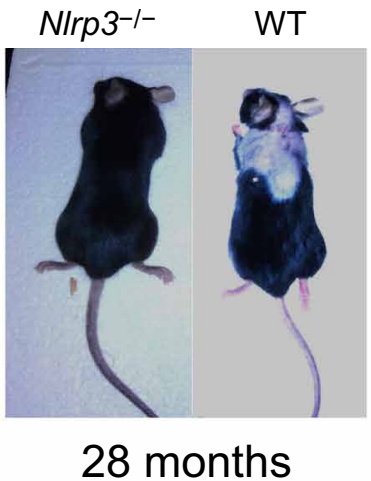

F

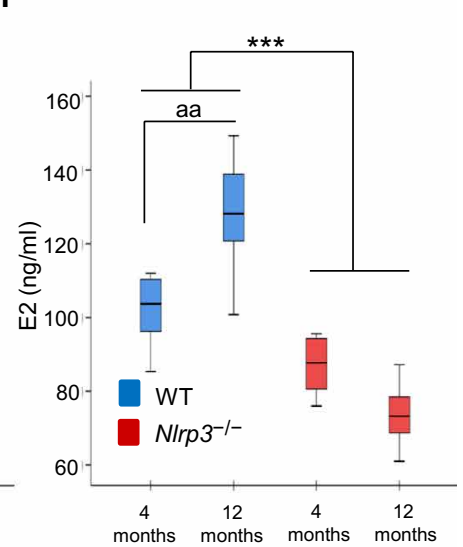

E

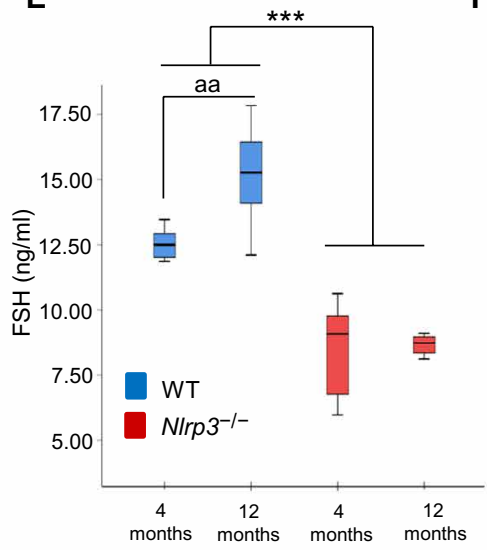

H

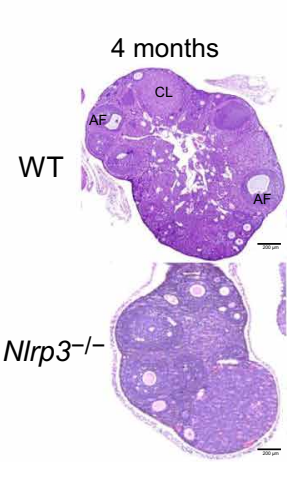

I

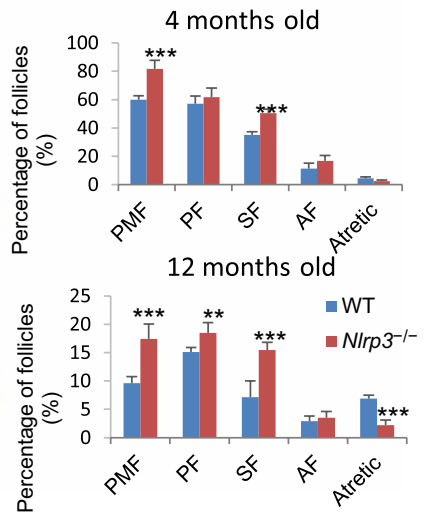

Fig. 2. NLRP3 signaling suppression in mice extends life span and improves hormonal status in female mice. (A) Kaplan-Meier graph showing a significant increase in $n$ that pertains to the maximum life span in WT mice compared with Nlrp $3^{-1-}$ mice. (B) Body weights of the groups over time. (C) Representative photographs of 28-month-old mice. (D) Mean serum AMH levels by enzyme-linked immunosorbent assay (ELISA) and ovarian AMH protein levels (top) measured by Western blot (WB) to evaluate the progression of ovarian reserve during aging in WT mice compared with N/rp $3^{-1-}$ mice. On top, ovarian AMH protein levels. (E and F) Analysis of serum concentrations of FSH and E2 measured by ELISA. $N=8$ per group. (G) Representative images showing comparative size and weights of uterine horns in WT and N/rp $3^{-/-}$mice. (H and I) Representative micrographs of 4- and 12-month-old WT and Nlrp3 ${ }^{-/-}$ovarian sections. The number of ovarian follicles at developmental stages [primordial follicle (PMF), primary follicle (PF), secondary follicle (SF), and antral follicle (AF); asterisks in the image, PMF and arrowhead, atretic follicle] was assessed in every fifth serial section of WT and NIrp ${ }^{-/-} . N=15$ to 20 per group. Data are shown as means \pm SD. ${ }^{* *} P<0.005,{ }^{* * *} P<0.001$, aaa $P<0.001, N / r p 3^{-/-}$versus WT mice; ${ }^{\text {aa }} P<0.01,4$-month-old versus 12-month-old mice. Photo credit: Beatriz Castejón-Vega, Institute of Molecular, Cell and Systems Biology, University of Glasgow (C); Mario D. Cordero, Cátedra de Reproducción y Genética Humana del Instituto para el Estudio de la Biología de la Reproducción Humana (INEBIR)-Universidad Europea del Atlántico (UNEATLANTICO)Fundación Universitaria Iberoamericana (FUNIBER) (G). 
A
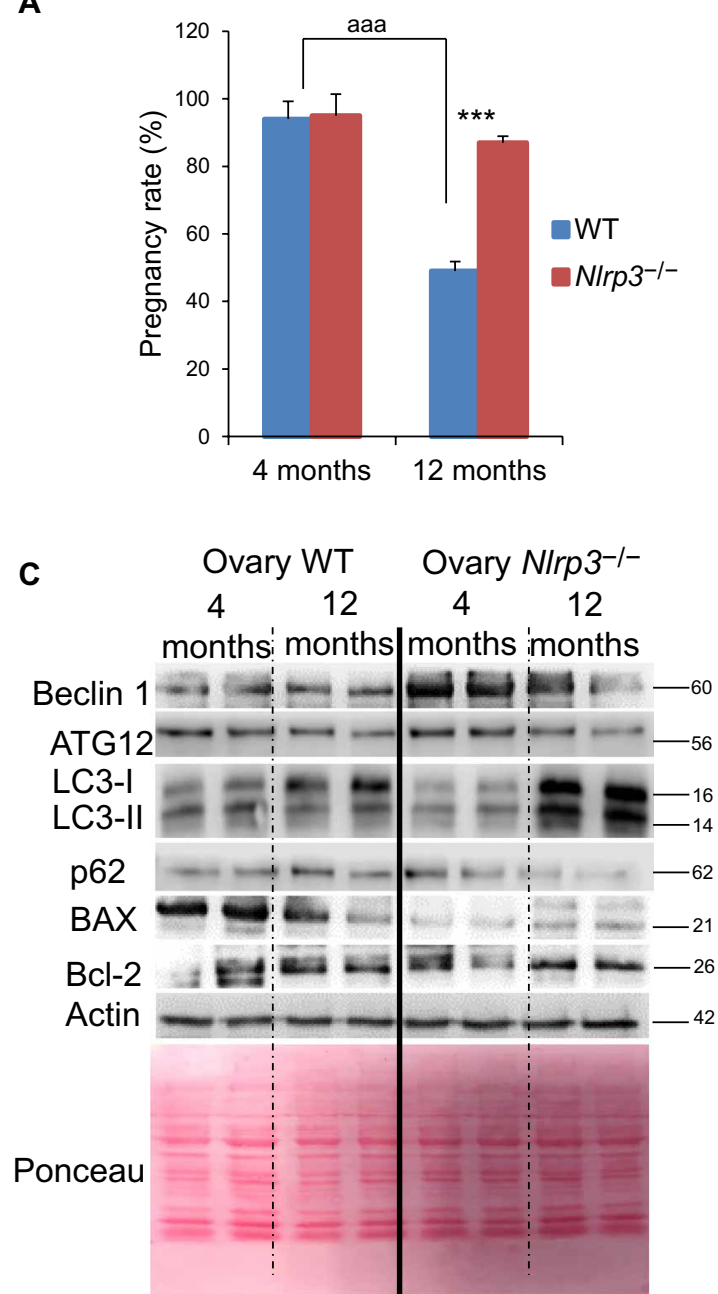
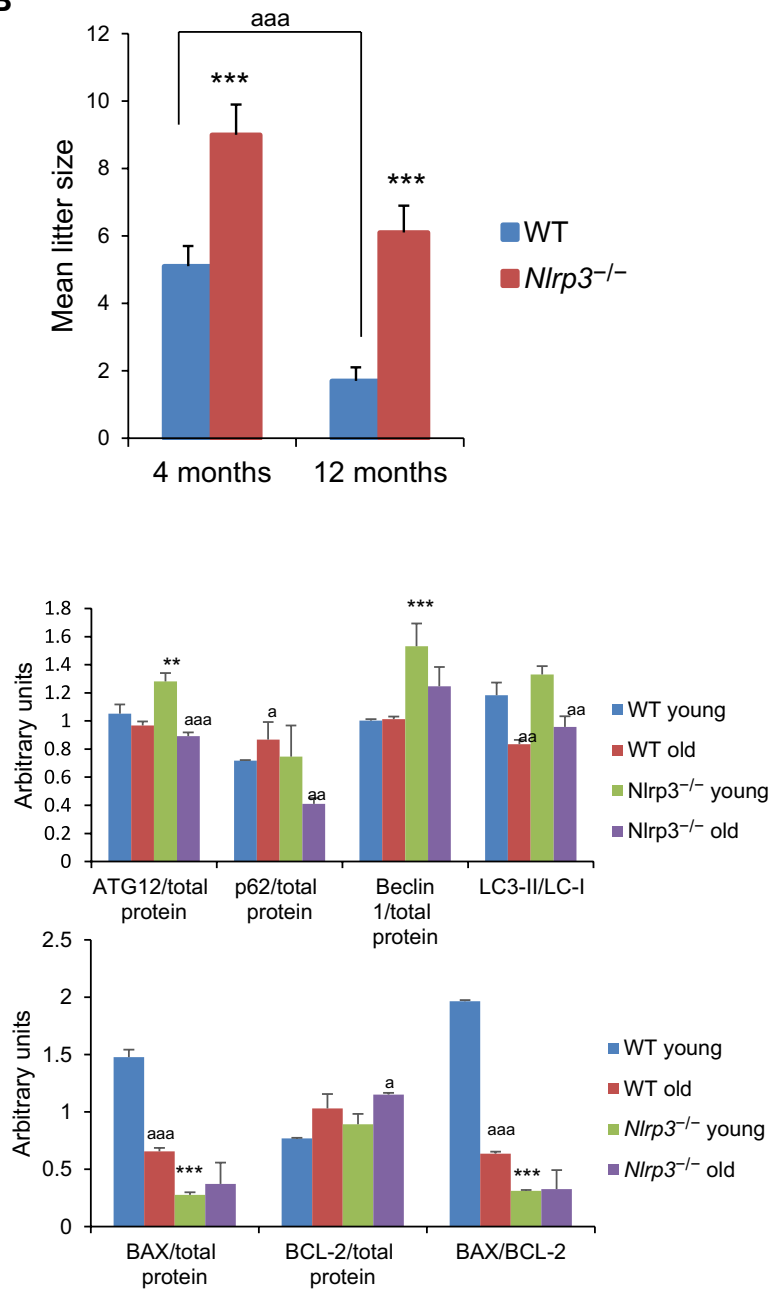

Fig. 3. Nlrp3 deletion improves reproductive rate and autophagy pathway. Pregnancy rate (A) and mean litter size (B) in aged WT and Nlrp $3^{-/-}$mice. Data are shown as means \pm SD. ${ }^{* * *} P<0.001, N / r p 3^{-/-}$versus WT mice; ${ }^{\text {aaa }} P<0.001$, 4-month-old versus 12 -month-old mice. (C) Western blot analysis with representative blot including BECLIN 1, ATG12, LC3, p62, BAX, and Bcl-2 levels in the ovary of 4- and 12-month-old WT and N/rp3 ${ }^{-/-}$. Densitometric analysis is shown as means \pm SD, $n=10$ mice per group and age. ${ }^{* *} P<0.005$ and ${ }^{* * *} P<0.001$; WT versus NIrp $3^{-1-} ;{ }^{\text {aaa }} P<0.001,{ }^{\text {aa }} P<0.01,{ }^{\text {a }} P<0.05$, young versus old mice.

protein B-cell lymphoma 2 (BCL-2) (Fig. 3C). Despite reduced levels of IL-1 $\beta$ and IL-18 and no differences in the levels of the other inflammasomes between 12-month-old Nlrp $3^{-/-}$ovaries compared to WT (fig. S7, A and B), we observed higher levels of TNF and IL-6 in the ovaries of mutant mice (fig. S7C). These results suggest that the loss of NLRP3 has a role in the reproductive aging independent of other inflammatory pathways.

\section{Age-associated change of ovary gene expression profile was prevented in $\mathrm{NIrp3}^{-/-}$mice}

We performed a microarray expression profiling of WT and $\mathrm{Nlrp}^{-/-}$to identify the molecular mechanisms underlying the preserved health of the ovaries in 12-month-old mutant mice. There were 1453 differentially expressed transcripts between $\mathrm{Nlrp}^{-/-}$and WT mice: 691 transcripts were up-regulated, and 762 transcripts were down-regulated (with cutoffs of fold change $\geq 2$ and $P<0.05$ ). To find the affected biological processes, we used Kyoto Encyclopedia of Genes and Genomes (KEGG) pathway as the annotation source. This enrichment analysis revealed that overexpressed genes in $\mathrm{Nlrp}^{-/-}$samples belonged to the following pathways: "cell cycle," "oocyte meiosis," "progesterone-mediated oocyte maturation," "PI3K-AKT signaling pathway," "mismatch repair," and "biosynthesis of amino acids" (Fig. 4A). Consistent with the knowledge that aging is associated with a decrease in the efficiency of repair and accumulation of DNA damage $(15,16)$, genes involved in mismatch repair pathways were up-regulated in old $\mathrm{Nlrp}^{-I-}$ ovaries (Fig. 4A). These results suggest delayed cellular senescence and increased capacity of oocytes for DNA repair in mutant ovaries (17). To reinforce this concept, the expression value of the genes involved in these pathways was further analyzed. Genes associated with the follicle development (e.g., BMP15 and Pla2g4a), ovarian responses to hormones (e.g., Fshr), or meiotic M phase (e.g., AURKA and Bub1) were up-regulated in all replicates (Fig. 4B). Other interesting changes were the up-regulation of Cyclin B1 (Ccnb1) and Ccnb2, which are required for embryo development and ovulation of mature oocytes, respectively. All these changes indicate an improved meiosis pathway and oocyte maturation in $\mathrm{Nlrp}^{-/-}$mice during aging. 
A
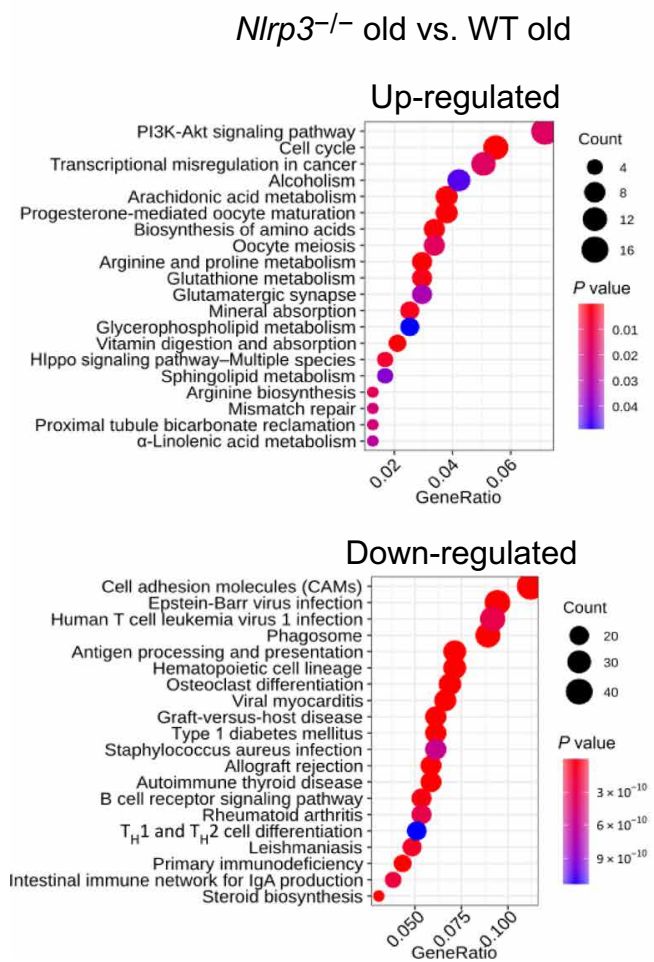

B
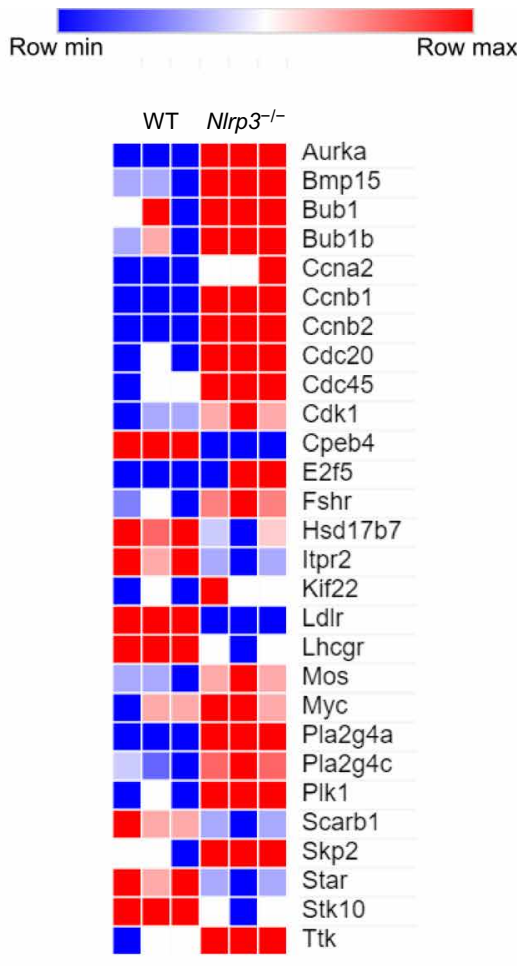

Fig. 4. Transcriptional changes in ovaries from old WT and $\mathbf{N} / r p 3^{-1-}$ mice. (A) The most enriched KEGG pathways are shown for both overexpressed (691) and underexpressed genes (762). Differentially expressed genes were extracted with fold change $>2$ and $P<0.05$ (Bea). GeneRatio shows the relative frequency of genes that belong to that pathway. (B) Heatmap that shows the expression values (z scores) of differently expressed protein-coding genes involved in the following pathways: cell cycle, oocyte meiosis, and progesterone-mediated oocyte maturation, separated by the three replicates of aged WT and N/rp $3^{-/-}$.

\section{Pharmacological inhibition of NLRP3 rescues female fertility during aging}

We tested the effect of the NLRP3 inhibitor, MCC950, in female mice. Because fertility in mice declines around 8 months of age, we treated 8-month-old mice with vehicle and MCC950 [20 mg/kg per day, intraperitoneally (ip)] for 12 weeks. No significant changes in body weight were observed between both groups (Fig. 5A). Vehicletreated mice showed significantly reduced AMH serum levels compared to MCC950-exposed mice (Fig. 5B). Serum levels of FSH and E2 were also decreased by MCC950 treatment (Fig. 5, C and D), findings that were consistent with histological staining showing higher percentages of follicles and lower percentages of atretic follicles in MCC950-treated compared to vehicle-administrated mice (Fig. 5, E and F). These data revealed a gradual decline in female fertility in vehicle-treated mice, whereas age-matched mice in the MCC950-treated group remained fertile. The pregnancy rate was markedly increased in MCC950-treated mice compared to the vehicle group (Fig. 5G), although differences in the mean litter size were not observed (Fig. $5 \mathrm{H}$ ).

In line with data from $\mathrm{Asc}^{-/-}$mice in which we observed an independent effect of the NLRP3 inhibition, we also analyzed the effects of 16673-34-0, an intermediate substrate produced during glyburide synthesis, which was shown to inhibit NLRP3 inflammasome complex formation by interfering with events involved in NLRP3 conformational changes secondary to activation or binding to ASC (18). Again, 8-month-old female mice were treated with vehicle or $16673-34-0$ (100 mg/kg per day, ip) for 12 weeks. No signif- icant changes were observed in body weight between groups either (fig. 8A). Notably, AMH, FSH, and E2 serum levels were not significantly different between both groups (fig. S8, B to D). Last, there were also no differences in pregnancy rate and mean litter size (fig. S8, E and F).

\section{DISCUSSION}

Aging of the world population is as undeniable as its profound health and economic consequences (19). The increased average age at which women have children and the consequent increase in problems related with fertility are the principal causes that lead to an increase in the demand for assisted reproduction technologies $(20,21)$. However, the molecular mechanisms of ovarian aging, which may provide new clues for protection from aging-specific female reproductive decline, are still not well understood. Inflammation and autophagy are highly associated with aging, and many rejuvenation strategies rely on anti-inflammatory and autophagy inductions (22). Increased systemic inflammation is commonly associated with metabolic alterations, including the appearance of increased adiposity, insulin resistance, and dyslipidemia, responses that are likely critical determinants in the shortening of life span and overall health. Many of these metabolic alterations have been associated with NLRP3 inflammasome activation $(1,9,10,23)$. However, little is known about the role of NLRP3 during female aging and fertility. Effective fertility requires a fine balance between pro- and antiinflammatory mediators and reproductive hormones. Inflammation 
A

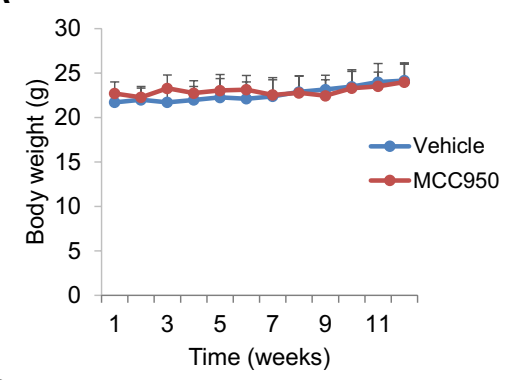

C

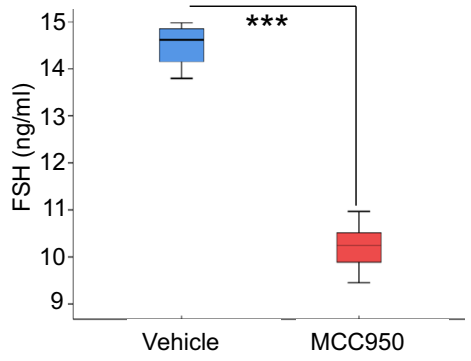

E

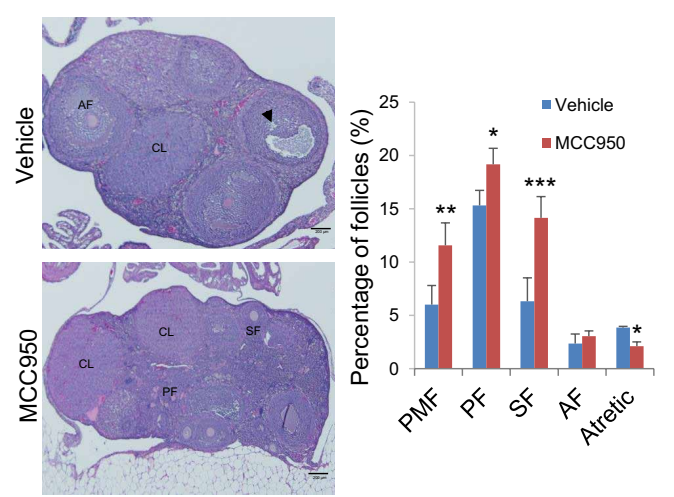

B

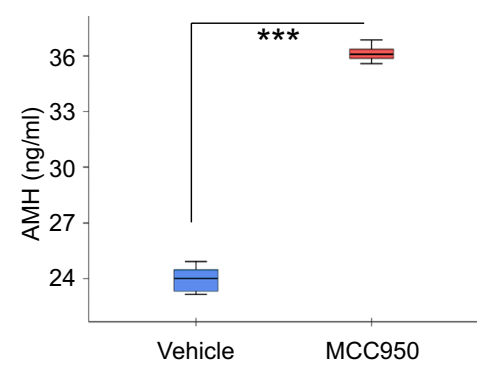

D
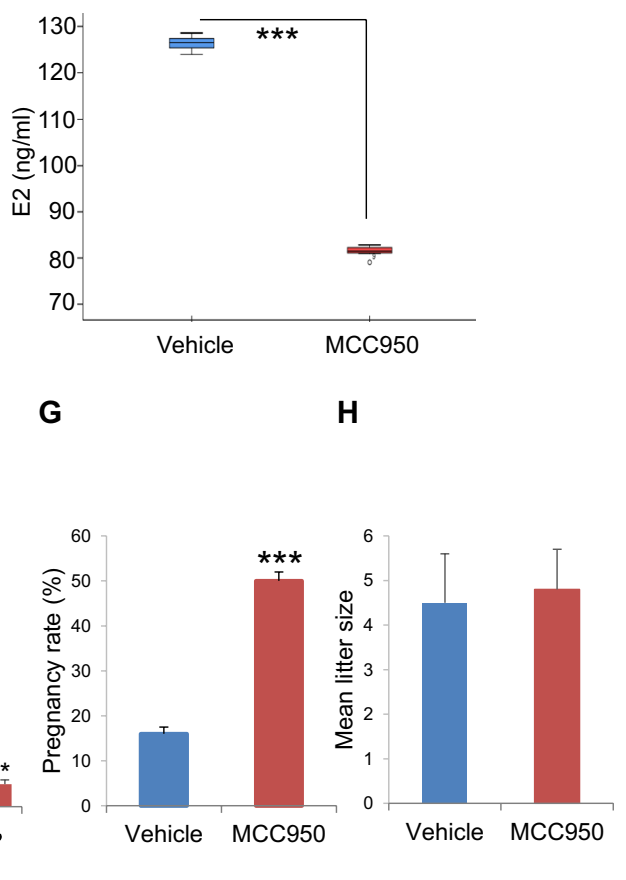

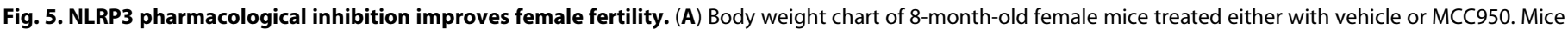

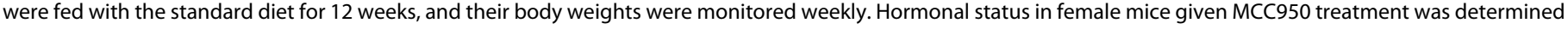

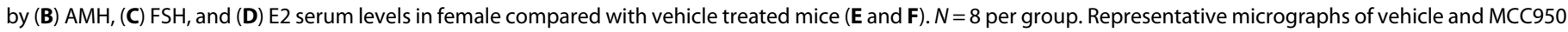

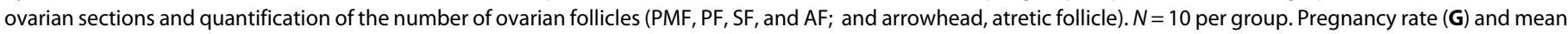

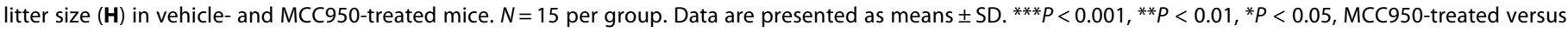
vehicle-treated mice.

has been associated with female infertility and metabolic dysfunction, suggesting that early and chronic inflammation may trigger early menopause, which is associated with the cessation of the ovarian function (24). In the current study, we provide evidence showing that the NLRP3 inflammasome is an important determinant of fertility in human and aged female mice. We show that the expression of NLRP3 and other components of the complex rapidly increase in the ovary during aging and human GCs, in a human condition of accelerated ovarian aging. Moreover, we show the localization of NLRP3 protein within oocytes and GCs throughout follicular development, which is consistent with the localization of inflammatory protein (6). NLRP3 was also expressed in the glandular epithelium of the uterus. Since inflammation has been implicated in the regulation of uterine endometrium, reduction of growth, and viability of preimplantation stage embryos leading to miscarriages (25), the role of NLRP3 in the uterus during aging will need to be explored.
Inflamm-aging, the long-term result of the chronic stimulation of the innate immune system with continuous damage during the aging process, has been associated with patients with DOR in which levels of several cytokines are increased (26). Our data reveal increased levels of TNF- $\alpha$ in serum samples with no significant changes in IL-1 $\beta$ and IL-18. mRNA expression levels of NLRP3 were increased in patients' GCs. Furthermore, the reproductive advantage of $\mathrm{Nlrp}^{-/-}$mice compared with WT mice was corroborated by the transcriptomic analysis, which showed that different pathways associated with meiosis, oocyte growth, and maturation were improved in Nlrp3 null mice. According to this, NLRP3 has a specific role in the ovarian aging process. Our data also demonstrate that the genetic inhibition of NLRP3, but not in ASC, enhances ovulation and pregnancy rates and improve ovarian endocrine function in an apparently inflammasome-independent manner, whereas ovaries from Nlrp3 gain-of-function mutant mice have hormone levels 
consistent with reduction of fertility. These data suggest that NLRP3 has differential roles in innate immunity and reproduction. Our data are consistent with previous reports showing the preventive role of Nlrp3 deletion but not caspase-1/11 or ASC in other tissues and pathologies $(27,28)$. Furthermore, $N \operatorname{lrp} 3^{-/-}$female mice showed increased inflammatory cytokine levels in the ovary; however, despite this, ovarian aging was prevented by Nlrp3 deletion, which indicates an inflamm-aging-independent role of NLRP3.

Nlrp3 ablation also showed an increase in autophagy in aged ovaries consistent with previous data in other tissues $(9,29)$. It is known that autophagy efficiency is reduced during aging in many tissues (30). The autophagy pathway has been linked to the preservation of the oocyte longevity by maintaining the endowment of female germ cells before the establishment of primordial follicle (PMF) pools in the ovary $(13,31)$. This mechanism may be the key to the improvement of ovarian life span induced by the inhibition of NLRP3. Furthermore, the support of many of the strategies has been shown to improve the reproductive aging and ovarian life span through the improvement of autophagy $(31,32,33)$.

The present study further demonstrates a metabolic regulatory effect of the NLRP3 inflammasome in females in the reproductive hormone during the equivalent perimenopause period in female mice. Mice are sexually mature by 3 to 6 months of age, and the human endocrine equivalent of human perimenopause is 8 to 9 months of age (34). During this biological time frame, many biochemical changes mark reproductive aging, including increased levels of estrogen, FSH, and metabolic and inflammatory factors $(35,36)$. Our middle-aged $N l r p 3^{-/-}$female mice showed the hormonal status of the perimenopause stage, decreased risk factors of age-related diseases. Female KO mice showed improved glucose tolerance, a nonsignificant reduction of leptin levels, and an increase of adiponectin levels.

Several NLRP3 inhibitors have been identified and studied in different disease states. While several of these inhibitors have been shown to have a specific direct action on NLRP3, others have indirect inhibitory effects (18). MCC950 is a specific small-molecule inhibitor of this inflammasome, although the molecular mechanisms of action of this compound have not been fully elucidated (18). Our study shows that MCC950 improves fertility in female middle-aged mice similar to Nlrp3 KO mice.

We acknowledge the limitations of using patients with DOR only. The use of GCs from healthy women with different age during the biological aging could corroborate our hypothesis. However, it is difficult to obtain samples from healthy individuals at different ages for ethical reasons. On the other hand, we have studied the effect of the ablation or constitutive activation of NLRP3 where we cannot separate local out of the systemic effects. Thus, future investigations should focus on ovarian-specific, ovarian-restricted manipulation of the inflammasomes.

In conclusion, NLRP3 inhibition attenuates ovarian aging and prolongs fertility in female mice. NLRP3 ablation improved hormonal and metabolic characteristics related to female reproductive aging, improved autophagy, and reduced apoptosis Therefore, prevention of the ovarian aging process through multiple mechanisms by NLRP3 inhibition could attenuate the reproductive aging in female mice. Taking into account the observed increased expression of NLRP3 in the ovary during normal aging and in patients with DOR, NLRP3 inhibition offers a promising therapeutic target to maintain female fertility during aging.

\section{MATERIALS AND METHODS \\ Ethical statements}

For the human study, written informed consent and the approval of the Research Ethics Committee of the Virgen Macarena University Hospital, Seville, Spain were obtained, according to the principles of the Declaration of Helsinki. Animal studies were performed in accordance with European Union guidelines (2010/63/EU) and the corresponding Spanish regulations for the use of laboratory animals in chronic experiments (RD 53/2013 on the care of experimental animals). All experiments were approved by the local institutional animal care committee.

\section{Patients}

The study consisted of 20 women from our fertility clinic diagnosed with DOR according to the Bologna criteria (37) and 20 healthy women from our oocyte donation program. Inclusion criteria were healthy women younger than 40 years old, without a previous pregnancy at term, an abnormal ovarian reserve test (antral follicle count of less than five to seven follicles or FSH $>10 \mathrm{mIU} / \mathrm{ml}$ and E2 $>60 \mathrm{pg} / \mathrm{ml}$ on day 3 of the cycle), and previously characterized poor ovarian response stimulation cycle [three or less oocytes with a conventional stimulation protocol and E2 $<500 \mathrm{pg} / \mathrm{ml}$ on the day human chorionic gonadotropin (hCG) was given]. Exclusion criteria were a significant ongoing medical problem. Healthy controls were younger than 35 years old, with antral follicle counts $>10$ follicles, serum levels of FSH $<10 \mathrm{IU} / \mathrm{ml}$, and serum E2 $<60 \mathrm{pg} / \mathrm{ml}$ on day 3 of the cycle and no previous medical history of infertility. All patients included in the study were associated with idiopathic ovarian insufficiency without antecedents of iatrogenic or gonadotoxic events.

All patients and controls had taken no drugs or vitamin/nutritional supplements during the 3 weeks before to the collection of blood samples. Clinical data were obtained in the fertility clinic of Instituto de la Biología de la Reproducción Humana (INEBIR) following the committee opinion advice of the Sociedad Española de Fertilidad (www.sefertilidad.net), the European Society of Human Reproduction and Embryology (www.eshre.eu), and the American Society for Reproductive Medicine (www.asrm.org).

\section{GC isolation}

Mural GCs were obtained from 20 patients with DOR and 20 healthy women after oocyte retrieval from 20 patients undergoing in vitro fertilization (IVF) treatment at INEBIR. Ovarian stimulation was accomplished using a short protocol strategy combining gonadotropinreleasing hormone antagonist short protocol (Cetrorelix acetate, Cetrotide, Merck Serono Europe Limited, Spain), recombinant FSH (GONAL-f 75 UI, Merck Serono Europe Limited, Spain), urinary human menopausal gonadotropin (HMG-Lepori 75 UI, Angelini Farmacéutica, S.A, Spain) and recombinant hCG (Ovitrelle $250 \mathrm{mi}-$ crograms, Merck Serono Europe Limited, Spain), or leuprorelin acetate (Procrin $1 \mathrm{mg} / 0.2 \mathrm{ml}$, AbbVie Spain S.L.U.) to initiate final follicle maturation.

Preparation of IVF-GCs for culture started when the medical team decided to administer hCG trigger to optimize the final oocyte maturation. Thirty-six hours before oocyte retrieval, light paraffin culture oil and filtered in sterility (OVOIL culture oil, Vitrolife, Sweden) are added to a petri dish (60 $\mathrm{mm}$ by $15 \mathrm{~mm}$ dish, Nunclon Delta) and preequilibrated in a $\mathrm{CO}_{2}$ incubator at $+37.3^{\circ} \mathrm{C}$ and $6 \%$ $\mathrm{CO}_{2}$. Twenty-four hours before oocyte retrieval, culture medium drops (G-IVF PLUS, Vitrolife, Sweden) were prepared in a petri 
dish and covered with the preequilibrated oil; the medium drops contain oocyte-granulosa clusters obtained during oocyte retrieval. In addition to culture medium preparation, G-MOPS PLUS (Vitrolife, Sweden) medium aliquots were prepared and used to wash and isolate GCs during oocyte retrieval; two tubes with $8 \mathrm{ml}$ of G-MOPS PLUS on each one and one tube with $1 \mathrm{ml}$ of G-MOPS PLUS. Tubes were stored in the $\mathrm{CO}_{2}$ incubator and were firmly closed to prevent $\mathrm{pH}$ and osmolarity changes.

The day of oocyte retrieval, the embryologist team worked on a safety work hood with a heated surface (K-SYSTEMS IVF Workstations, CooperSurgical Medical Devices) with all the laboratory material needed to isolate the oocyte-cumulus complexes and GC clusters: 60-mm embryo-tested petri dishes and sterile glass Pasteur pipettes (150-mm Short Soda Glass Pasteur, Hunter Scientific). During oocyte retrieval, the gynecologist aspirated the follicular fluid of each follicle and deposited it in sterile conical tubes (Falcon 15-ml Polystyrene Centrifuge Tube) previously heated in a thermoblock; all the conical tubes were transferred to the embryo laboratory in a thermoblock to ensure a constant temperature once the oocytes were aspirated. Simultaneously, the embryologist received the tubes from the operating room, and their contents were deposited in 60-mm preheated petri dishes on the safety work hood. Once the cumulus-oocytes were identified under the microscope, they were transferred to a petri dish containing $8 \mathrm{ml}$ of G-MOPS PLUS to be washed from blood cells and follicular fluid with sterile glass Pasteur pipettes. At the end of oocyte retrieval, every cumulusoocyte complex was transferred to the culture medium drops previously equilibrated in the $\mathrm{CO}_{2}$ incubator. At the same time, free granulose cells were identified in the follicular fluid and transferred to the 1-ml G-MOPS PLUS tube. These tubes were centrifuged at $3200 \mathrm{rpm}$ for $5 \mathrm{~min}$; the supernatants were discarded, and compact pellets of granulose cells were obtained. The pellets are resuspended in $0.5 \mathrm{ml}$ of RNAlater solution (RNAlater, Sigma-Aldrich) to stabilize RNA and prevent its degradation and stored in a freezer at $-20^{\circ} \mathrm{C}$.

\section{Animals}

For all experiments, only female mice were used. Young and old $\mathrm{Nlrp3}^{-/-}$and $A s \mathrm{C}^{-/-}$mice [C57BL/6J background, provided by $\mathrm{B}$. Ryffel and originally generated and characterized in the laboratory of J. Tschopp (38)] and WT/Nlrp3 $3^{+/+} / \mathrm{Asc}^{+/+}$littermate controls (also on C57BL/6J background), weighing 25 to $30 \mathrm{~g}$, were maintained on a regular 12-hour light/12-hour dark cycle. All groups had ad libitum access to their prescribed diet and water throughout the whole study. Body weight was monitored weekly. Animal rooms were maintained at $20^{\circ}$ to $22^{\circ} \mathrm{C}$ with 30 to $70 \%$ relative humidity.

To generate gain-of-function NLRP3 in myeloid cells and WT littermate controls, we bred NOMID mice $\left(N \operatorname{lrp} 3^{\text {D301NneoR }}\right.$ Jax \#017971) with lysozyme M-Cre (Lyz2 $2^{\text {tm1(cre)Ifo } / J ~ J a x \# 004781 ; ~}$ C57BL/6J background). Ovaries were harvested from 2-week-old mice and were immediately frozen in liquid nitrogen. The weights of WT littermate control mice were in the range of 6 to $7 \mathrm{~g}$, and NOMID mice were in the range of 3 to $4 \mathrm{~g}$, consistent with previous reports.

For all experiments with NLRP3 inhibitors, female C57BL6/J mice (to maintain the comparative background) from the Jackson laboratory were maintained on a regular 12-hour light/12-hour dark cycle at $20^{\circ}$ to $22^{\circ} \mathrm{C}$. Treatments were started at 8 months of age after randomization into four groups. This study was distributed in two substudies: vehicle versus MCC950 and vehicle versus
16673-34-0. These groups correspond to the following treatment: (i) standard diet with intraperitoneal vehicle (saline) treatment (vehicle group) from Teklad Global 14\% Protein Rodent Maintenance Diet, Harlan Laboratories (carbohydrate:protein:fat ratio of 48:14:4 percent of $\mathrm{kcal}$ ), (ii) standard diet with MCC950 treatment (MCC950 group), (iii) vehicle group, and (iv) standard diet with 16673-34-0 treatment (16673-34-0 group). MCC950 was administered by intraperitoneal route at previously characterized doses: $20 \mathrm{mg} / \mathrm{kg}$ daily and 16673-34-0 by intraperitoneal route at $100 \mathrm{mg} / \mathrm{kg}$ daily $(39,40)$. All groups had ad libitum access to their prescribed diet and water throughout the study. Body weight and food intake were monitored weekly.

\section{Reagents}

Monoclonal antibodies specific for Beclin 1 and p62 were purchased from Sigma-Aldrich (Saint Louis, USA). The anti-glyceraldehyde3-phosphate dehydrogenase monoclonal antibody was acquired from Calbiochem-Merck Chemicals Ltd. (Nottingham, UK). Last, anti-Bcl-2, anti-Bax, anti-ATG12, and anti-MAP-LC3 antibodies were obtained from Santa Cruz Biotechnology. Anti-AMH antibody was obtained from Abbexa (Cambridge, UK). NLRP3 inhibitors MCC950 and 16673-34-0 were obtained from Sigma-Aldrich (Saint Louis, USA) and R\&D Systems (Minneapolis, USA), respectively. A cocktail of protease inhibitors (cOmplete Protease Inhibitor Cocktail) was purchased from Boehringer Mannheim (Indianapolis, IN). The Immun-Star horseradish peroxidase (HRP) substrate kit was obtained from Bio-Rad Laboratories Inc. (Hercules, CA).

\section{Real-time quantitative polymerase chain reaction}

The expression of the NLRP3 gene was analyzed by SYBR Green quantitative polymerase chain reaction (PCR) of mRNA extracted from GCs according to the previously described methodology (41). Briefly, total cellular RNA was purified from the cells by the TRIsure method (Bioline, London, UK). RNA concentration was determined spectrophotometrically. RNA samples were subsequently reversetranscribed to cDNA using the QuantiTect Reverse Transcription Kit (QIAGEN, Hilden, Germany). PCR amplifications were conducted with primers targeting NLRP3 (NM_004895.4) and $\beta$-actin, used as an internal control. Thermal cycling conditions used were denaturation at $95^{\circ} \mathrm{C}$ for $20 \mathrm{~s}, 40$ cycles of priming at $54^{\circ} \mathrm{C}$ for $20 \mathrm{~s}$, and elongation at $72^{\circ} \mathrm{C}$ for $20 \mathrm{~s}$. All reactions were performed in duplicate, and reaction mixes without RNA were used as negative controls in each run. Absence of contaminating genomic DNA was confirmed by setting up control reactions with RNA that had not been reverse transcribed. Fold changes in the expression of genes of interest were calculated using the $\Delta \Delta C$ t method.

\section{Mouse longevity study}

The longevity study was previously described (9). Briefly, WT and $N \operatorname{lrp} 3^{-/-}$female mice (C57BL/6J background), weighing 25 to $30 \mathrm{~g}$, were maintained on a regular 12-hour light/12-hour dark cycle. Mice were housed in groups of four to eight same-sex littermates under specific pathogen-free conditions. Individuals were monitored daily and weighed monthly but were otherwise left undisturbed until they died. Survival was assessed using male and female mice, and all animals were dead by the time of this report. KaplanMeier survival curves were constructed using known birth and death dates, and differences between groups were evaluated using the log-rank test. A separate group of female mice were sacrificed 
at different ages between 4 and 12 months to study ovaries (histology and Western blots).

\section{Breeding}

WT, $\mathrm{Nlrp3}^{-1-}$, and $\mathrm{Asc}^{-1-}$ female mice were individually caged with a WT male mice of confirmed fertility for a period of 1 month. Female mice were monitored and weighed daily. Female mice that gained $3 \mathrm{~g}$ of weight were considered pregnant and sacrificed. The number of fetuses per female was quantified.

\section{Glucose tolerance test}

Glucose tolerance tests were performed by fasting the mice overnight for 16 hours and then injecting glucose $(1 \mathrm{~g} / \mathrm{kg})$ intraperitoneally. Glucose measurements were performed using a Bayer Contour blood glucose meter and test strips.

\section{Serum AMH measurement}

Blood samples were taken from the heart by cardiac puncture, preferably from the ventricle, and serum samples were extracted and kept at $-80^{\circ} \mathrm{C}$ until use. Measurements were performed using enzyme-linked immunosorbent assay (ELISA) according to the manufacturer's instructions (Beckman Coulter).

\section{Leptin and adiponectin}

Serum levels of leptin and adiponectin were assayed in duplicate using commercial ELISA kits (R\&D Systems, Minneapolis, USA).

\section{Serum biomarkers}

Serum levels of glucose, triglycerides, cholesterol, uric acid, aspartate aminotransferase, alanine aminotransferase, and creatine kinase were assayed using commercial kits (Randox Laboratories, Antrim, UK).

\section{Immunoblotting}

Western blotting was performed using standard methods. After protein transfer, the membrane was incubated with various primary antibodies diluted at 1:1000 and then with the corresponding secondary antibodies coupled to HRP at a 1:10,000 dilution. Ponceau $S$ staining was selected as a loading control. Specific protein complexes were identified using an Immun-Star HRP substrate kit (Bio-Rad Laboratories Inc., Hercules, CA, USA).

\section{Histological study}

After anesthesia of mice, ovaries were excised and immediately placed in 10\% neutral-buffered formalin. The ovaries were embedded in paraffin, serially sectioned at a thickness of $5 \mu \mathrm{m}$, and stained with hematoxylin and eosin. Each section was scanned for morphological analysis, and every fifth section was used to quantify the total number of follicles classified by states: the number of PMF and primary, secondary, and antral follicles (42). The middle section of each ovary was used for a representative visual comparison in the figure.

\section{Immunostaining}

Ovaries were dissected, fixed in $4 \%$ paraformaldehyde, and embedded in paraffin. We baked $4-\mu \mathrm{m}$ sections at $60^{\circ} \mathrm{C}$ for 1 hour, deparaffinized in xylenes, and rehydrated into phosphate-buffered saline (PBS). Antigen retrieval was done in boiling citrate buffer [10 mM sodium citrate ( $\mathrm{pH}$ 6.0)] for $15 \mathrm{~min}$. Sections were blocked in PBS containing $2 \%$ bovine serum albumin $+0.05 \%$ Triton X-100 and 5\% normal donkey serum for 1 hour at room temperature and then incubated with primary antibodies (NLRP3/NALP3 Antibody, Novus Biological) diluted in blocking solution overnight at $4^{\circ} \mathrm{C}$. After washing with PBS containing $0.2 \%$ Triton X-100, they were incubated with fluorescent secondary antibody (Alexa Fluor 488, Invitrogen) in blocking solution for 1 hour at room temperature, followed by PBS washes. The sections were then counterstained with ProLong Gold Antifade reagent with 4',6-diamidino-2-phenylindole (Invitrogen).

\section{Transcriptome analysis}

Transcriptomic analysis was previously described (9). Briefly, we used the Affymetrix Clariom S assay mouse. The raw data were analyzed by the Affymetrix software Transcriptome Analysis Console. Expression values were normalized by Signal Space TransformationRobust Microarray Analysis, and the mutant mice were compared with WT using three replicates for every analysis. Then, fold change and $P$ value were calculated for every gene by an unpaired one-way test (single factor) using the NMath package. A gene was considered differentially expressed when it had a fold change equal or higher than 2 and a $P$ value equal or lower than 0.05 using Fisher's exact test. Then, gene names of protein-coding genes were mapped to Ensembl identifiers using BioMart (https://pubmed.ncbi.nlm.nih. gov/19617889/), and functional enrichment was made using KEGG Pathway as annotation source with the R libraries biomaRt and clusterProfiler and a $P$ value threshold of 0.05 .

\section{Statistics}

The evaluation of normality was performed using the Shapiro-Wilk test. Then, statistical differences among the different groups were measured using either an unpaired Student's $t$ test or one-way analysis of variance (ANOVA) when appropriate, with Tukey's post hoc test when appropriate. All data are shown as means \pm SD. A $P$ value of $\leq 0.05$ was considered statistically significant. For these statistical analyses, we use Prism software version 5.0a (GraphPad, San Diego, CA). Asterisks in the figures represent the following: ${ }^{*} P<0.05$, ${ }^{* *} P<0.01$, and ${ }^{* * *} P<0.001$.

\section{SUPPLEMENTARY MATERIALS}

Supplementary material for this article is available at http://advances.sciencemag.org/cgi/ content/full/7/1/eabc7409/DC1

View/request a protocol for this paper from Bio-protocol.

\section{REFERENCES AND NOTES}

1. M. D. Cordero, M. R. Williams, B. Ryffel, AMP-activated protein kinase regulation of the NLRP3 inflammasome during aging. Trends Endocrinol. Metab. 29, 8-17 (2018).

2. P. May-Panloup, L. Boucret, J. M. Chao de la Barca, V. Desquiret-Dumas, V. Ferré-L'Hotellier, C. Morinière, P. Descamps, V. Procaccio, P. Reynier, Ovarian ageing: the role of mitochondria in oocytes and follicles. Hum. Reprod. Update 22, 725-743 (2016).

3. T. Takahashi, H. Igarashi, M. Amita, S. Hara, H. Kurachi, Cellular and molecular mechanisms of various types of oocyte aging. Reprod. Med. Biol. 10, 239-249 (2011).

4. S. Wang, Y. Zheng, J. Li, Y. Yu, W. Zhang, M. Song, Z. Liu, Z. Min, H. Hu, Y. Jing, X. He, L. Sun, L. Ma, C. R. Esteban, P. Chan, J. Qiao, Q. Zhou, J. C. Izpisua Belmonte, J. Qu, F. Tang, G. H. Li, Single-cell transcriptomic atlas of primate ovarian aging. Cell 180, 585-600.e19 (2020).

5. L. L. Cui, G. Yang, J. Pan, C. Zhang, Tumor necrosis factor $\alpha$ knockout increases fertility of mice. Theriogenology 75, 867-876 (2011).

6. S. Uri-Belapolsky, A. Shaish, E. Eliyahu, H. Grossman, M. Levi, D. Chuderland, L. Ninio-Many, N. Hasky, D. Shashar, T. Almog, M. Kandel-Kfir, D. Harats, R. Shalgi, Y. Kamari, Interleukin-1 deficiency prolongs ovarian lifespan in mice. Proc. Natl. Acad. Sci. U.S.A. 111, 12492-12497 (2014).

7. C. Wang, S. Hockerman, E. J. Jacobsen, Y. Alippe, S. R. Selness, H. R. Hope, J. L. Hirsch, S. J. Mnich, M. J. Saabye, W. F. Hood, S. L. Bonar, Y. Abu-Amer, A. Haimovich, 
H. M. Hoffman, J. B. Monahan, G. Mbalaviele, Selective inhibition of the p38 $\alpha$ MAPK-MK2 axis inhibits inflammatory cues including inflammasome priming signals. J. Exp. Med. 215, 1315-1325 (2018).

8. I. S. Afonina, Z. Zhong, M. Karin, R. Beyaert, Limiting inflammation-the negative regulation of NF- $\kappa B$ and the NLRP3 inflammasome. Nat. Immunol. 18, 861-869 (2017)

9. F. Marín-Aguilar, A. V. Lechuga-Vieco, E. Alcocer-Gómez, B. Castejón-Vega, J. Lucas, C. Garrido, A. Peralta-Garcia, A. J. Pérez-Pulido, A. Varela-López, J. L. Quiles, B. Ryffel, I. Flores, P. Bullón, J. Ruiz-Cabello, M. D. Cordero, NLRP3 inflammasome suppression improves longevity and prevents cardiac aging in male mice. Aging Cell 19, e13050 (2020).

10. Y. H. Youm, R. W. Grant, L. R. McCabe, D. C. Albarado, K. Y. Nguyen, A. Ravussin, P. Pistell, S. Newman, R. Carter, A. Laque, H. Münzberg, C. J. Rosen, D. K. Ingram, J. M. Salbaum, V. D. Dixit, Canonical Nlrp3 inflammasome links systemic low-grade inflammation to functional decline in aging. Cell Metab. 18, 519-532 (2013).

11. S. L. Bonar, S. D. Brydges, J. L. Mueller, M. D. McGeough, C. Pena, D. Chen, S. K. Grimston, C. L. Hickman-Brecks, S. Ravindran, A. McAlinden, D. V. Novack, D. L. Kastner, R. Civitelli, H. M. Hoffman, G. Mbalaviele, Constitutively activated NLRP3 inflammasome causes inflammation and abnormal skeletal development in mice. PLOS ONE 7, e35979 (2012).

12. J. O. Pyo, S. M. Yoo, H. H. Ahn, J. Nah, S. H. Hong, T. I. Kam, S. Jung, Y. K. Jung, Overexpression of Atg5 in mice activates autophagy and extends lifespan. Nat. Commun. 4, 2300 (2013)

13. A. E. Peters, B. P. Mihalas, E. G. Bromfield, S. D. Roman, B. Nixon, J. M. Sutherland, Autophagy in female fertility: A role in oxidative stress and aging. Antioxid. Redox Signal. 32, 550-568 (2020)

14. M. He, T. Zhang, Z. Zhu, S. Qin, H. Wang, L. Zhao, X. Zhang, J. Hu, J. Wen, H. Cai, Q. Xin Q. Guo, L. Lin, B. Zhou, H. Zhang, G. Xia, C. Wang, LSD1 contributes to programmed oocyte death by regulating the transcription of autophagy adaptor SQSTM1/p62. Aging Cell , e13102 (2020).

15. H. Wei, X. Liu, J. Yuan, L. Li, D. Zhang, X. Guo, L. Liu, S. Zhang, Age-specific gene expression profiles of rhesus monkey ovaries detected by microarray analysis. Biomed. Res. Int. 2015, 625192 (2015).

16. V. Gorbunova, A. Seluanov, Z. Mao, C. Hine, Changes in DNA repair during aging. Nucleic Acids Res. 35, 7466-7474 (2007).

17. J. M. Stringer, A. Winship, S. H. Liew, K. Hutt, The capacity of oocytes for DNA repair Cell. Mol. Life Sci. 75, 2777-2792 (2018).

18. A. Zahid, B. Li, A. J. K. Kombe, T. Jin, J. Tao, Pharmacological inhibitors of the NLRP3 inflammasome. Front. Immunol. 10, 2538 (2019).

19. M. Cristea, G. G. Noja, P. Stefea, A. L. Sala, The impact of population aging and public health support on EU labor markets. Int. J. Environ. Res. Public Health 17, 1439 (2020).

20. R. Lee, A. Mason; Members of the NTA Network, Is low fertility really a problem? Population aging, dependency, and consumption. Science 346, 229-234 (2014).

21. D. Carslake, P. Tynelius, G. J. van den Berg, G. Davey Smith, Associations of parental age with offspring all-cause and cause-specific adult mortality. Sci. Rep. 9, 17097 (2019).

22. T. Finkel, The metabolic regulation of aging. Nat. Med. 21, 1416-1423 (2015).

23. C. López-Otín, L. Galluzzi, J. M. P. Freije, F. Madeo, G. Kroemer, Metabolic control of longevity. Cell 166, 802-821 (2016).

24. M. R. Gubbels Bupp, T. Potluri, A. L. Fink, S. L. Klein, The confluence of sex hormones and aging on immunity. Front. Immunol. 9, 1269 (2018).

25. C. M. D. Marquez, J. A. Ibana, M. C. Velarde, The female reproduction and senescence nexus. Am. J. Reprod. Immunol. 77, e12646 (2017).

26. Y. Huang, C. Hu, H. Ye, R. Luo, X. Fu, X. Li, J. Huang, W. Chen, Y. Zheng, Inflamm-aging: A new mechanism affecting premature ovarian insufficiency. J. Immunol. Res. 2019, 8069898 (2019).

27. A. L. Chenery, R. Alhallaf, Z. Agha, J. Ajendra, J. E. Parkinson, M. M. Cooper, B. H. K. Chan, R. M. Eichenberger, L. A. Dent, A. A. B. Robertson, A. Kupz, D. Brough, A. Loukas, T. E. Sutherland, J. E. Allen, P. R. Giacomin, Inflammasome-independent role for NLRP3 in controlling innate antihelminth immunity and tissue repair in the lung. J. Immunol. 203, 2724-2734 (2019)

28. M. Bruchard, C. Rebé, V. Derangère, D. Togbé, B. Ryffel, R. Boidot, E. Humblin, A. Hamman F. Chalmin, H. Berger, A. Chevriaux, E. Limagne, L. Apetoh, F. Végran, F. Ghiringhelli, The receptor NLRP3 is a transcriptional regulator of TH2 differentiation. Nat. Immunol. 16, 859-870 (2015).

29. Y. Zhang, M. Sauler, A. S. Shinn, H. Gong, M. Haslip, P. Shan, P. Mannam, P. J. Lee, Endothelial PINK1 mediates the protective effects of NLRP3 deficiency during letha oxidant injury. J. Immunol. 192, 5296-5304 (2014).

30. D. C. Rubinsztein, G. Mariño, G. Kroemer, Autophagy and aging. Cell 146, 682-695 (2011).

31. T. R. Gawriluk, A. N. Hale, J. A. Flaws, C. P. Dillon, D. R. Green, E. B. Rucker III, Autophagy is a cell survival program for female germ cells in the murine ovary. Reproduction 141, 759-765 (2011).
32. H. Tamura, M. Kawamoto, S. Sato, I. Tamura, R. Maekawa, T. Taketani, H. Aasada, E. Takaki, A. Nakai, R. J. Reiter, N. Sugino, Long-term melatonin treatment delays ovarian aging J. Pineal. Res. 62, (2017)

33. X. Dou, Y. Sun, J. Li, J. Zhang, D. Hao, W. Liu, R. Wu, F. Kong, X. Peng, J. Li, Short-term rapamycin treatment increases ovarian lifespan in young and middle-aged female mice. Aging Cell 16, 825-836 (2017).

34. R. Diaz Brinton, Minireview: translational animal models of human menopause: Challenges and emerging opportunities. Endocrinology 153, 3571-3578 (2012).

35. N. Santoro, J. R. Brown, T. Adel, J. H. Skurnick, Characterization of reproductive hormonal dynamics in the perimenopause. J. Clin. Endocrinol. Metab. 81, 1495-1501 (1996).

36. G. Palla, C. Ramírez-Morán, M. M. Montt-Guevara, D. Salazar-Pousada, J. Shortrede, T. Simoncini, I. Grijalva-Grijalva, F. R. Pérez-López, P. Chedraui, Perimenopause, body fat, metabolism and menopausal symptoms in relation to serum markers of adiposity, inflammation and digestive metabolism. J. Endocrinol. Invest. 43, 809-820 (2020).

37. A. P. Ferraretti, A. La Marca, B. C. Fauser, B. Tarlatzis, G. Nargund, L. Gianaroli; ESHRE working group on Poor Ovarian Response Definition, ESHRE consensus on the definition of "poor response" to ovarian stimulation for in vitro fertilization: The Bologna criteria. Hum. Reprod. 26, 1616-1624 (2011).

38. F. Martinon, V. Pétrilli, A. Mayor, A. Tardivel, J. Tschopp, Gout-associated uric acid crystals activate the NALP3 inflammasome. Nature 440, 237-241 (2006).

39. R. C. Coll, A. A. Robertson, J. J. Chae, S. C. Higgins, R. Muñoz-Planillo, M. C. Inserra, I. Vetter L. S. Dungan, B. G. Monks, A. Stutz, D. E. Croker, M. S. Butler, M. Haneklaus, C. E. Sutton, G. Núñez, E. Latz, D. L. Kastner, K. H. Mills, S. L. Masters, K. Schroder, M. A. Cooper, L. A. O'Neill, A small-molecule inhibitor of the NLRP3 inflammasome for the treatment of inflammatory diseases. Nat. Med. 21, 248-255 (2015).

40. C. Marchetti, J. Chojnacki, S. Toldo, E. Mezzaroma, N. Tranchida, S. W. Rose, M. Federici, B. W. Van Tassell, S. Zhang, A. Abbate, A novel pharmacologic inhibitor of the NLRP3 inflammasome limits myocardial injury after ischemia-reperfusion in the mouse. J. Cardiovasc. Pharmacol. 63, 316-322 (2014).

41. P. Bullón, F. J. Cano-García, E. Alcocer-Gómez, A. Varela-López, L. Roman-Malo, R. J. Ruiz-Salmerón, J. L. Quiles, J. M. Navarro-Pando, M. Battino, J. Ruiz-Cabello, L. J. Jiménez-Borreguero, M. D. Cordero, Could NLRP3-inflammasome be a cardiovascular risk biomarker in acute myocardial infarction patients? Antioxid. Redox Signal. 27, 269-275 (2017).

42. Y. Morita, G. I. Perez, D. V. Maravei, K. I. Tilly, J. L. Tilly, Targeted expression of Bcl-2 in mouse oocytes inhibits ovarian follicle atresia and prevents spontaneous and chemotherapy-induced oocyte apoptosis in vitro. Mol. Endocrinol. 13, 841-850 (1999).

\section{Acknowledgments}

Funding: This study was supported by a grant from the Andalusian regional government (Grupo de Investigacion Junta de Andalucia CTS113, Consejería de Salud de la Junta de Andalucia: PI-0036-2014) and European funding in Region Centre-Val de Loire (FEDER N 2016-00110366 BIO-TARGET and EX005756 BIO-TARGET II). G.M. is supported by NIH/NIAMS AR068972 and AR076758 grants. Author contributions: M.D.C. conceived the study. M.D.C., J.M.N.-P., A.S., and E.A.-G. designed the experiments. B.C.-V. and C.W. carried out sample isolation and experiment, analyzed the data, and prepared the figures. J.M.N.-P. and P.B. performed human studies and prepared the figures. M.C.-H. and M.M.-R. carried out and studied embryos. E.N.-V. and J.M. performed immunostaining studies. H.M.H. and G.M provided NOMID mice and samples. B.R. provided Nlrp3 ${ }^{-/-}$mice and samples. A.J.P.-P. performed transcriptomic analysis. M.D.C. and B.R. wrote the manuscript. All authors discussed the results and implications and commented on the manuscript at all stages. Competing interests: G.M. is a consultant for Aclaris Therapeutics Inc. The authors declare no other competing interests. Data and materials availability: All data needed to evaluate the conclusions in the paper are present in the paper and/or the Supplementary Materials. Additional data related to this paper may be requested from the authors.

\section{Submitted 11 May 2020}

Accepted 9 November 2020

Published 1 January 2021

$10.1126 /$ sciadv.abc7409

Citation: J. M. Navarro-Pando, E. Alcocer-Gómez, B. Castejón-Vega, E. Navarro-Villarán M. Condés-Hervás, M. Mundi-Roldan, J. Muntané, A. J. Pérez-Pulido, P. Bullon, C. Wang H. M. Hoffman, A. Sanz, G. Mbalaviele, B. Ryffel, M. D. Cordero, Inhibition of the NLRP3 inflammasome prevents ovarian aging. Sci. Adv. 7, eabc7409 (2021). 